\title{
Rearrangement of $o$-(pivaloylaminomethyl)benzaldehydes: an experimental and computational study
}

\author{
Csilla Hargitai ${ }^{1}$, Györgyi Koványi-Lax ${ }^{1}$, Tamás Nagy ${ }^{1}$, Péter Ábrányi-Balogh ${ }^{2}$, \\ András Dancsó ${ }^{1}$, Gábor Tóth ${ }^{1,3}$, Judit Halász ${ }^{1}$, Angéla Pandur ${ }^{1}$, Gyula Simig ${ }^{1}$ \\ and Balázs Volk ${ }^{* 1}, \S$
}

\section{Full Research Paper}

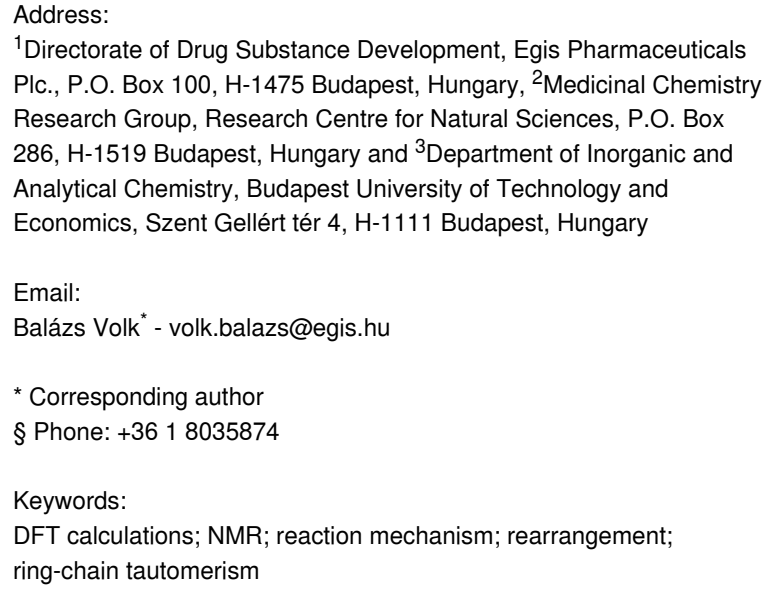

${ }^{1}$ Directorate of Drug Substance Development, Egis Pharmaceuticals Plc., P.O. Box 100, H-1475 Budapest, Hungary, ${ }^{2}$ Medicinal Chemistry Research Group, Research Centre for Natural Sciences, P.O. Box 286, $\mathrm{H}-1519$ Budapest, Hungary and ${ }^{3}$ Department of Inorganic and Analytical Chemistry, Budapest University of Technology and Economics, Szent Gellért tér 4, H-1111 Budapest, Hungary

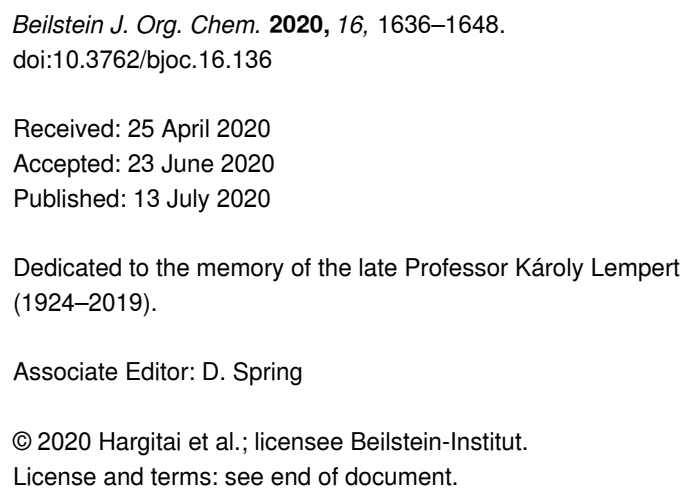

\begin{abstract}
Treatment of alkoxy-substituted $o$-(pivaloylaminomethyl)benzaldehydes under acidic conditions resulted in the formation of the regioisomeric aldehydes and/or dimer-like products. Detailed NMR studies and single-crystal X-ray measurements supported the structure elucidation of the compounds. DFT calculations were also carried out to clarify the reaction mechanism, and to explain the observed product distributions and structural variances in the dimer-like products. Studies on the transformation of unsubstituted $o$-(pivaloylaminomethyl)benzaldehyde under similar conditions were presented as well.
\end{abstract}

\section{Introduction}

In a preliminary publication [1] we disclosed that methylenedioxy-substituted $o$-(pivaloylaminomethyl)benzaldehyde (1a), when kept in dichloromethane (DCM) in the presence of a catalytic amount ( 0.13 equiv) of trifluoroacetic acid (TFA) for $72 \mathrm{~h}$ at room temperature, gave isomeric aldehyde $\mathbf{2 a}(48 \%)$ and the dimer-like racemic product 3a $(11 \%)$. Both transformations were rationalized by the intermediacy of the isoindole $4 \mathbf{a}$ (Scheme 1).

The formation of aldehyde $\mathbf{2 a}$ can be explained by a protonation of the ring tautomer 1a, followed by an acid-catalyzed water elimination to afford intermediate isoindole $4 \mathbf{a}$ [2-6]. 
<smiles>N=PNCc1ccc2c(c1C=O)OCO2</smiles>

1a

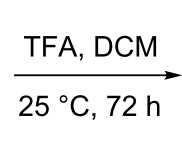

$72 \mathrm{~h}$<smiles>O=CNc1ccc2c(c1CN=P)OCO2</smiles>

$2 a(48 \%)$<smiles></smiles>

$\downarrow$<smiles>Cc1ccc2c(c1C(C(=O)Nc1ccccc1)C1c3ccc4c(c3CN1P)OCO4)OCO2</smiles>

Scheme 1: Rearrangement of methylenedioxy-substituted aminoaldehyde $\mathbf{1 a}$ to regioisomer $\mathbf{2 a}$ and formation of the dimer-like product $\mathbf{3 a}$.

Then, the addition of water to the sterically less-hindered site of the latter compound followed by ring opening resulted in the rearranged aldehyde $\mathbf{2 a}$ [1].

As regards the formation of dimer-like product 3a, the tendency of pyrrole $[7,8]$, indole [8], and isoindole $[3,9,10]$ to dimerize and polymerize was observed long ago. A repeatedly mentioned example was the formation of type $\mathbf{5}$ dimers under various conditions. They were first isolated during the synthesis of 1-arylisoindoles 6 by hydrogenation of $o$-cyanobenzophenones $\mathbf{7}$ in the presence of Raney nickel (Ra-Ni), sometimes as the main product, depending on the activity of the catalyst [10] (Scheme 2).

The oxidative dimerization of 1-phenylisoindole (6a) to compound 5a took place under various conditions: when refluxing in benzene in the presence of air [5,11], during an attempted nitrosation (with sodium nitrite in acetic acid), and in Mannich reactions [12]. For the formation of dimers $\mathbf{5}$, various mecha- nisms were envisaged. Nevertheless, the formation of any dimer-like product structurally similar to $\mathbf{3 a}$ has not been observed so far.

In this report we describe our efforts to extend the reaction described in Scheme 1 to further $o$-(pivaloylaminomethyl)benzaldehydes and to support the results by density functional theory (DFT) calculations, single-crystal X-ray measurements and comprehensive NMR studies.

\section{Results and Discussion Acid-catalyzed transformations of compounds 1a-d}

First we kept compounds 1a and 1b [2] in DCM in the presence of a catalytic amount ( 0.1 equiv) of TFA for $24 \mathrm{~h}$ at room temperature (Scheme 3 ) and the results are summarized in Table 1. In the case of aldehyde 1a, the yields obtained under these conditions were similar to those of the reaction mentioned<smiles>N#Cc1ccccc1C(=O)Br</smiles>

7

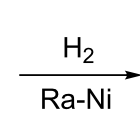<smiles>NCc1ccccc1C(=O)Br</smiles><smiles>[Al]C1=NCc2ccccc21</smiles>

\begin{tabular}{c|c} 
& $\mathrm{Ar}$ \\
\hline a & $\mathrm{Ph}$ \\
\hline b & $4-\mathrm{Me}-\mathrm{C}_{6} \mathrm{H}_{4}$ \\
\hline c & $4-\mathrm{MeO}-\mathrm{C}_{6} \mathrm{H}_{4}$ \\
\hline
\end{tabular}<smiles>C=CC</smiles><smiles>[Al+]=Cc1[nH]cc2ccccc12</smiles>

6<smiles>BrC1=N/C(=C2/N=C(Br)c3ccccc32)c2ccccc21</smiles>

Scheme 2: Synthesis of 1-arylisoindoles 6 and formation of dimers 5. 


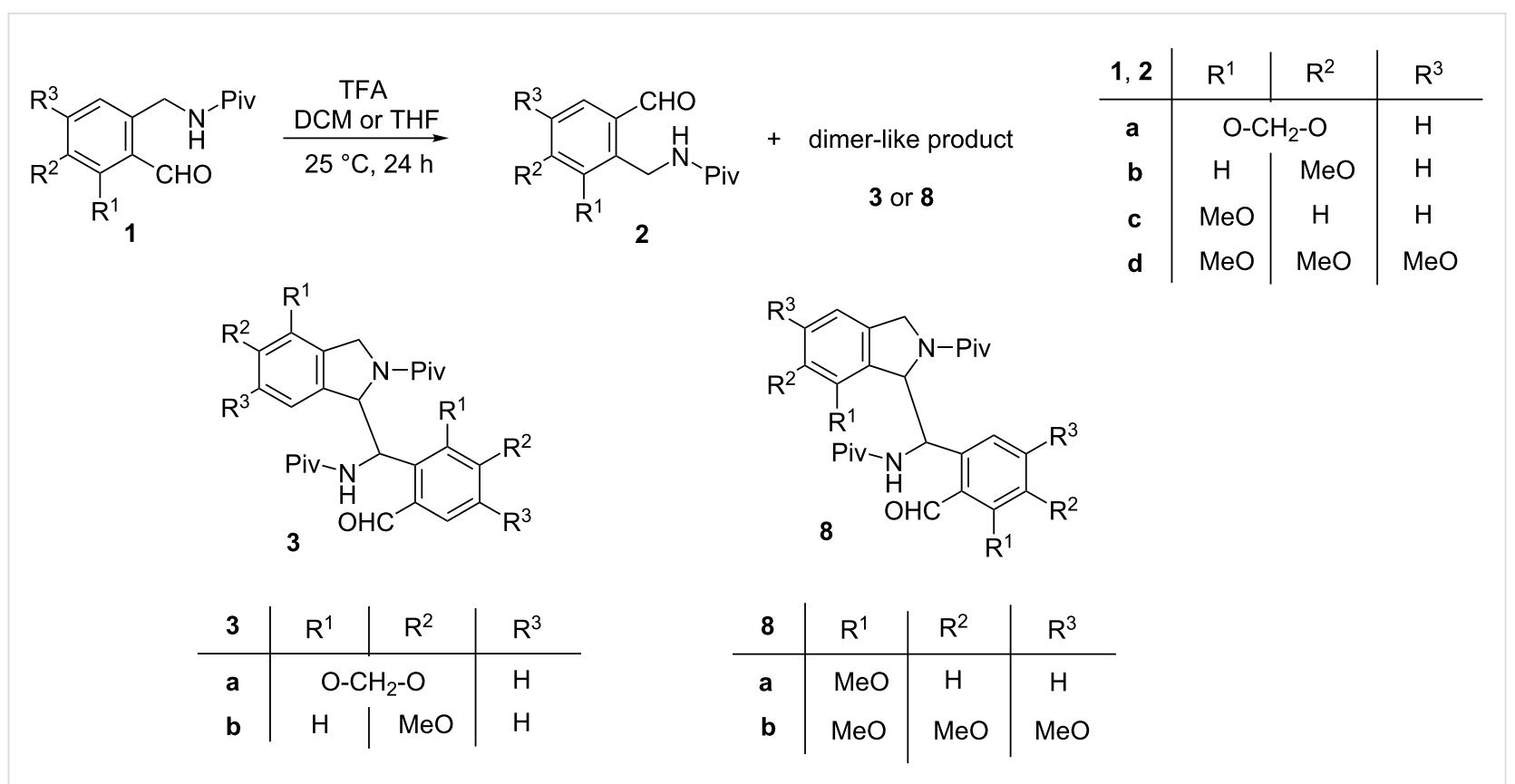

Scheme 3: Rearrangement of aminoaldehydes $\mathbf{1}$ to regioisomers 2 and formation of dimer-like products $\mathbf{3}$ and $\mathbf{8}$.

Table 1: Yields of rearranged aldehydes 2 and dimer-like products 3 and 8 in two different solvents.

\begin{tabular}{|c|c|c|c|c|c|c|c|c|}
\hline \multirow[t]{2}{*}{ starting material } & \multicolumn{4}{|c|}{ yield of products in DCM } & \multicolumn{4}{|c|}{ yield of products in THF } \\
\hline & 2 & yield (\%) & & yield (\%) & 2 & yield (\%) & & yield (\%) \\
\hline $1 a$ & $\mathbf{a}$ & 51 & $3 a$ & 13 & $\mathbf{a}$ & 59 & $3 a$ & 4 \\
\hline $1 b$ & b & 6 & $3 b$ & 43 & b & 35 & $3 b$ & 19 \\
\hline 1c & c & traces & $8 a$ & 8 & c & traces & $8 a$ & 7 \\
\hline 1d & d & - & $8 b$ & 10 & d & - & $8 b$ & 14 \\
\hline
\end{tabular}

above (Scheme 1). The treatment of derivative 1b, which possesses a methoxy group in the position para to the pivaloylaminomethyl moiety, resulted in the formation of significantly more of the dimer-like compound $\mathbf{3 b}$ as the major product and only a small amount of the aldehyde $\mathbf{2 b}$. When the reactions were carried out under the same conditions in tetrahydrofuran (THF) instead of DCM, substantially less dimer-like product $\mathbf{3 a}$ or $\mathbf{3 b}$ was formed in favor of the rearranged aldehyde $\mathbf{2 a}$ or $\mathbf{2 b}$.

When starting from aldehyde 1c [2], containing the methoxy function in the ortho position of the formyl moiety and meta to the pivaloylaminomethyl group, a practically full conversion of 1c was achieved in both solvents. However, only traces of an isomeric aldehyde (most likely $\mathbf{2 c}$, based on analogy with $\mathbf{2 a , b}$ ) could be detected by LC-MS besides several dimer-like products. The major one (8a, Scheme 3 ) could be isolated in a pure form (Table 1). In the case of the trimethoxy derivative $\mathbf{1 d}$ (pre- pared similarly to 1a-c, see Experimental), ca. $90 \%$ conversion was achieved in both solvents and the formation of the isomeric aldehyde 2d was not observed at all. As the only product, the dimer-like compound $\mathbf{8 b}$ could be isolated and characterized. The structure determination of products $\mathbf{3 b}$ and $\mathbf{8 b}$ was also supported by single-crystal X-ray measurements. These compounds were obtained as racemates and Figure 1 shows those enantiomers in which the chiral center of the isoindoline moiety possesses an $R$ configuration. All attempts to grow appropriate single crystals from derivative $\mathbf{8 a}$ were unsuccessful.

It has to be emphasized that theoretically, the formation of four dimer-like regioisomers could be expected from aldehydes $\mathbf{1 a - d}$, each of them as the mixture of two diastereomeric racemates. Although HPLC-MS measurements indeed indicated the presence of isomeric dimers in the crude product mixtures, only the major isomers $\mathbf{3 a}, \mathbf{b}$, and $\mathbf{8 a}, \mathbf{b}$ could be isolated. 

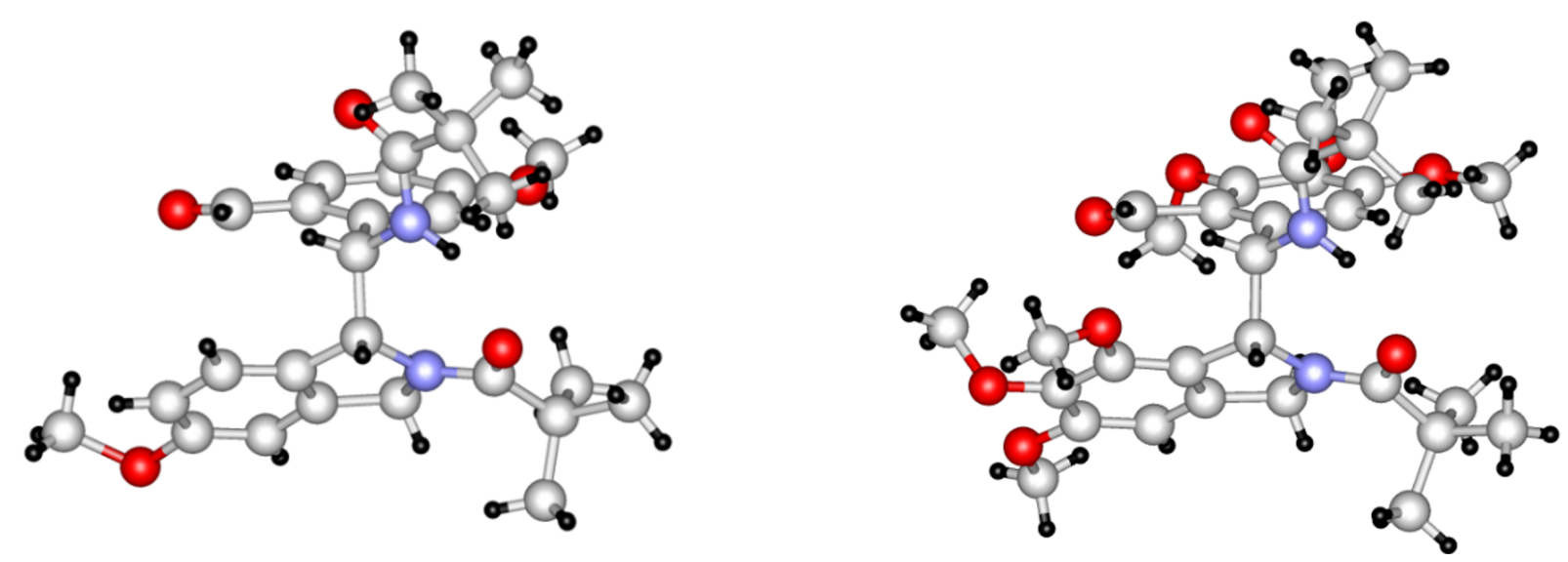

Figure 1: X-ray structures of compounds $\mathbf{3 b}$ (left) and $\mathbf{8 b}$ (right).

The main structural difference between the dimer-like products $\mathbf{3 a}, \mathbf{b}$ and $\mathbf{8 a}, \mathbf{b}$ concerns the position of the linkage of the orthoformylated $N$-pivaloylaminobenzyl moiety to the isoindoline building block. In the former products $\mathbf{3 a}, \mathbf{b}$ it is attached to the sterically less hindered, while in the latter compounds $\mathbf{8 a}, \mathbf{b}$ to the more hindered site of the isoindoline part.

\section{Proposed mechanism for the formation of re-} arranged aldehydes and dimer-like products

The formation of the rearranged aldehydes $\mathbf{2 a}, \mathbf{b}$ can be explained by the protonation of ring tautomers $\mathbf{9}$ to $\mathbf{1 0}$ (Scheme 4), followed by a water elimination, and subsequent deprotonation of cations $\mathbf{1 1}$ to afford isoindoles 4 [3-5]. The protonation of the latter [6], followed by the attack of water at position 1 of cations 12, and subsequent deprotonation of intermediates $\mathbf{1 3}$, results in hydroxyisoindolines $\mathbf{1 1}$, which can finally tautomerize to aldehydes $\mathbf{2 a}, \mathbf{b}$. In the previous report, we have demonstrated the existence of an equilibrium in the course of the transformation of 1a to $\mathbf{2 a}$ by trapping isoindole intermediate $\mathbf{4 a}$ with $N$-phenylmaleimide as a dienophile in the acid-catalyzed reaction of both aldehydes 1a and 2a [1]. Moreover, as a reverse reaction, the formation of aldehyde 1a was observed in the transformation of aldehyde 2a under similar conditions [1]. However, this equilibrium is obviously influenced by the formation of the dimer-like products.

The formation of the dimer-like products $\mathbf{3 a}$ and $\mathbf{3} \mathbf{b}$ can be rationalized by the electrophilic attack of cations $\mathbf{1 2 a}, \mathbf{b}$ at posi-<smiles>[R]c1cc(CN[N+]=[W])c(C=O)c([R])c1[R]</smiles><smiles>[R]c1cc2c(c([R])c1[R])C(O)N([Pb])C2</smiles>

\begin{tabular}{c|c|c|c} 
& $\mathrm{R}^{1}$ & $\mathrm{R}^{2}$ & $\mathrm{R}^{3}$ \\
\hline $\mathbf{a}$ & \multicolumn{2}{|c|}{$\mathrm{O}-\mathrm{CH}_{2}-\mathrm{O}$} & $\mathrm{H}$ \\
$\mathbf{b}$ & $\mathrm{H}$ & $\mathrm{MeO}$ & $\mathrm{H}$
\end{tabular}<smiles>[R]c1cc(C=O)c(CN[P+]=[NH2+])c([R])c1[R]</smiles><smiles>[R]c1cc2c(c([R])c1[R])CN([R16])C2O</smiles>

14

$\frac{+\mathrm{H}^{\oplus}}{-\mathrm{H}^{\oplus}}$<smiles>[R]c1cc2c(c([R])c1[R])C(O)N([Pb])C2</smiles><smiles>O=COCCO</smiles><smiles></smiles><smiles>[CH2+][C@H]1C=C[CH-]1</smiles><smiles>[R]c1cc2cn([R16])cc2c([R])c1[R]</smiles>
$-\mathrm{H}^{\oplus} \mid$

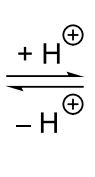<smiles>[R]c1cc2c(c([R])c1[R])CN([PH])[C@H]2[O-]</smiles>

13
$\frac{-\mathrm{H}_{2} \mathrm{O}}{+\mathrm{H}_{2} \mathrm{O}}$<smiles></smiles>

12

Scheme 4: Proposed mechanism of the isomerization of aldehydes 1 via isoindoles 4. 
tion 3 of isoindoles $\mathbf{4 a}, \mathbf{b}$ to give cations $\mathbf{1 5 a}, \mathbf{b}$ (Scheme 5). The reaction of the latter with water, followed by deprotonation leads to dimer-like compounds $\mathbf{1 6 a}, \mathbf{b}$, being the ring tautomers of the isolated products $\mathbf{3 a}$ and $\mathbf{3 b}$.

On the contrary, the formation of dimer-like products $\mathbf{8 a}$ and $\mathbf{8 b}$ can be explained by the electrophilic attack of cations 11c,d at position 1 (instead of position 3 ) of isoindoles $\mathbf{4 c}, \mathbf{d}$ to afford cations 17a,b (Scheme 6), which transform to the dimer-like products $\mathbf{5 a}, \mathbf{b}$ via their ring tautomers $\mathbf{1 8 a}, \mathbf{b}$.

The mechanism proposed for the formation of the intermediates $\mathbf{1 5 a}, \mathbf{b}$ and $\mathbf{1 7} \mathbf{a}, \mathbf{b}$ is supported by the fact that electrophilic substitution reactions of isoindole are well known in the litera- ture $[3,13-18]$ and these are analogous to that suggested for the dimerization of indole under acidic conditions (Scheme 7) [8]. Electrophilic attack of indole protonated at position 3 toward the position 3 of another indole molecule, followed by deprotonation affords dimer-like derivative 20. The fundamental difference of this transformation from that we observed in the case of isoindoles is that the attack of water at cation $\mathbf{1 9}$ and subsequent ring opening did not happen here.

\section{DFT calculations}

The proposed mechanism of the $\mathbf{1} \rightarrow \mathbf{2}$ rearrangement (Scheme 4) was investigated in detail by DFT level quantum chemical computations using the Gaussian 09 program package [19] (Figure 2). Optimization and frequency calculation have

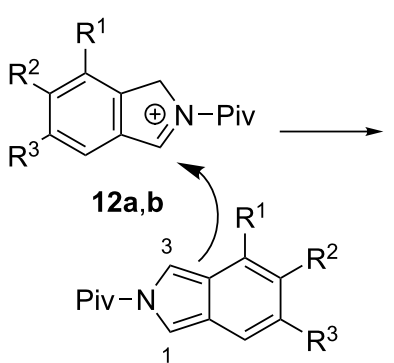

4a,b

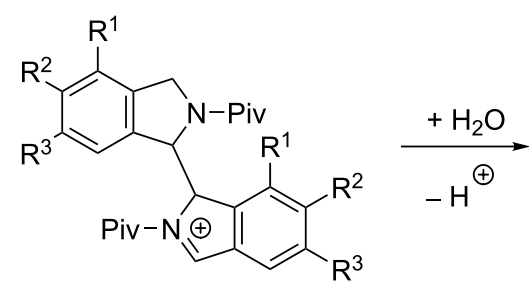

$15 a, b$<smiles>[R]c1cc2c(c([R])c1[R])CN([Y7])C2C1c2c(cc([R])c([R])c2[R])C(O)N1P(N)c1ccccc1</smiles>

$16 a, b$

\begin{tabular}{c|c|c|c} 
& $\mathrm{R}^{1}$ & $\mathrm{R}^{2}$ & $\mathrm{R}^{3}$ \\
\hline $\mathbf{a}$ & \multicolumn{2}{|c|}{$\mathrm{O}-\mathrm{CH}_{2}-\mathrm{O}$} & $\mathrm{H}$ \\
$\mathbf{b}$ & $\mathrm{H}$ & $\mathrm{MeO}$ & $\mathrm{H}$
\end{tabular}

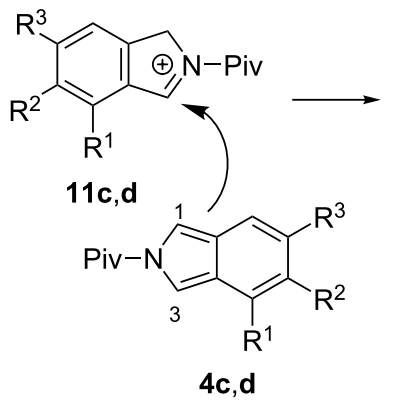<smiles></smiles>

\begin{tabular}{c|c|c|c|c}
$\mathbf{4 , 1 1}$ & $\mathbf{8 , 1 7 , 1 8}$ & $\mathrm{R}^{1}$ & $\mathrm{R}^{2}$ & $\mathrm{R}^{3}$ \\
\hline $\mathbf{c}$ & $\mathbf{a}$ & $\mathrm{MeO}$ & $\mathrm{H}$ & $\mathrm{H}$ \\
$\mathbf{d}$ & $\mathbf{b}$ & $\mathrm{MeO}$ & $\mathrm{MeO}$ & $\mathrm{MeO}$
\end{tabular}

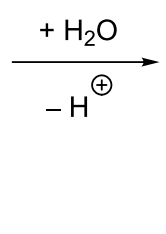

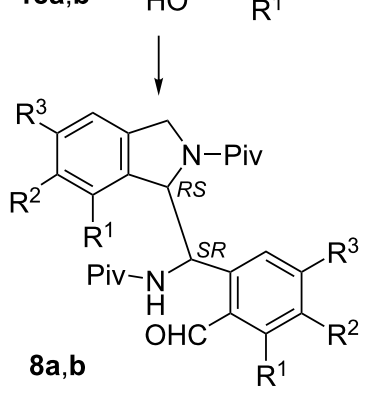


2<smiles>Cc1cc2c(cc1C)C(C)C(Cc1cc3ccccc3[nH]1)N2</smiles><smiles>CC=CC</smiles><smiles>C1=Nc2ccccc2C1C1Cc2ccccc2N1</smiles><smiles>C=CC</smiles><smiles>O=[N+]1CC(c2c[nH]c3ccccc23)Cc2ccccc21</smiles><smiles>CC(C)(C)O[13CH3]</smiles><smiles>[Y4]Cc1cccc2c1NC(O)C2C1Cc2ccccc2N1</smiles>

Scheme 7: Dimerization of indole under acidic conditions.

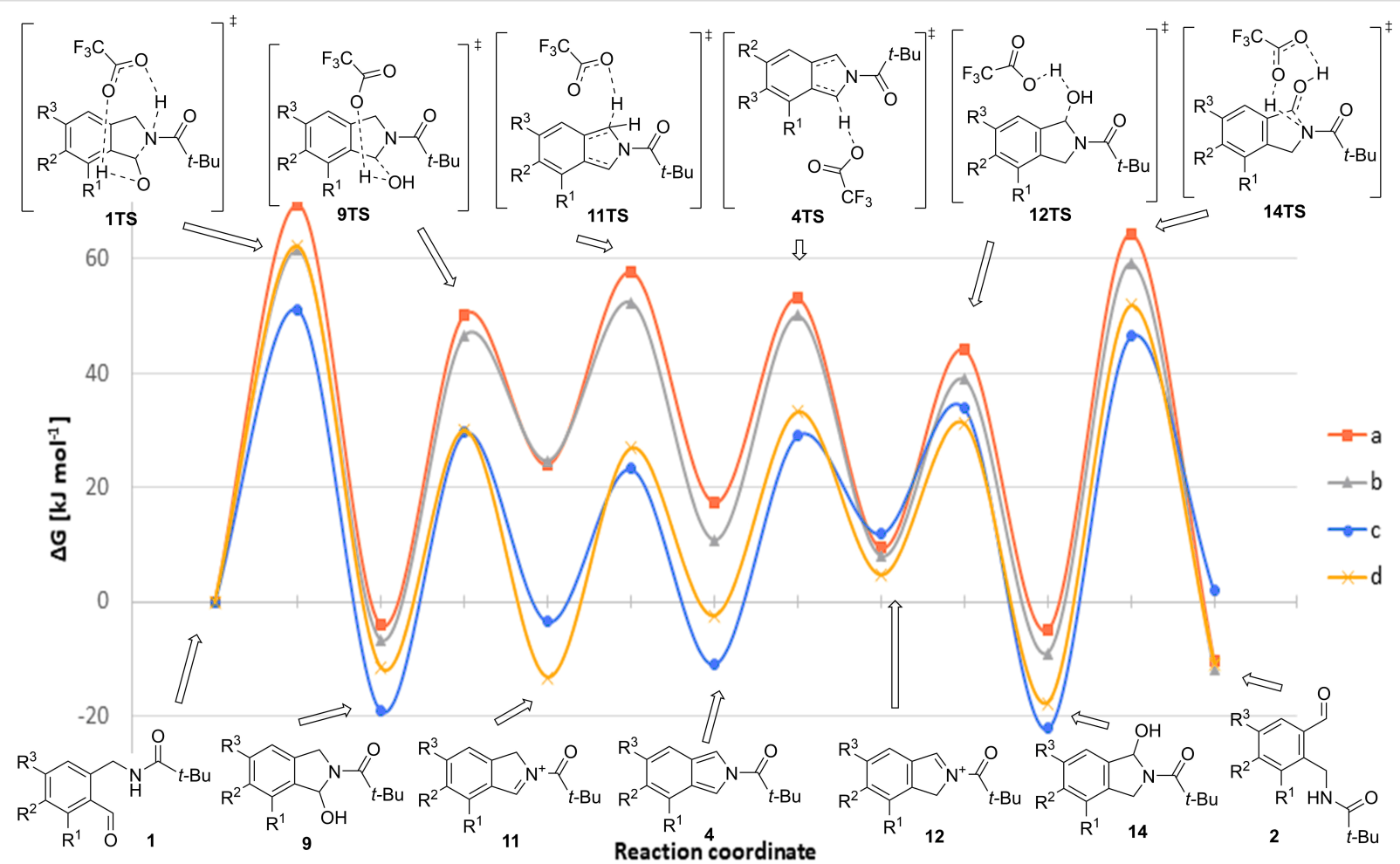

Figure 2: Gibbs free energy diagram for the $1 \rightarrow \mathbf{2}$ rearrangement.

been accomplished using the B3LYP/6-31+G $(\mathrm{d}, \mathrm{p})$ method [2022 ], followed by single point energy calculation with the B3LYP/6-311++G (3df,3pd) method [23,24], considering the solvent effect of DCM with the IEFPCM implicit solvent model [25] in both cases. When inspecting the Gibbs-free energy diagram of the transformation of aldehydes 1a-c (Figure 2, Table 2 and Table 3), it is noteworthy that the main trends until the formation of isoindole intermediates $\mathbf{4 a - c}$ are very similar. However, there is a significant difference in the $\mathbf{4} \rightarrow \mathbf{1 2}$ transformations. While in the case of aldehydes $\mathbf{1 a}$ and $\mathbf{1 b}$ this step is exergonic, for aldehyde $\mathbf{1 c}$ it is highly endergonic. This finding explains why, contrary to the formation of aldehydes $\mathbf{2 a}$ and $\mathbf{2} \mathbf{b}$, product $2 \mathbf{c}$ was practically not formed in the product mixture. Furthermore, it also explains the preference between the two regioisomeric cations $\mathbf{1 1}$ and $\mathbf{1 2}$ in the dimer-formation step. In the case of isoindoles $\mathbf{4 a}, \mathbf{b}$, cations $\mathbf{1 2} \mathbf{a}, \mathbf{b}$ are more stable than cations 11a,b, and the routes $\mathbf{1 1} \rightarrow \mathbf{4} \rightarrow \mathbf{1 2}$ leading to $\mathbf{1 2 a}, \mathrm{b}$ are exergonic. The simultaneous presence of isoindole $4 \mathbf{a}$ and cation 12a, or $4 \mathbf{b}$ and $\mathbf{1 2 b}$, respectively, gives rise to the formation of dimer-like products $\mathbf{3 a}$ or $\mathbf{3 b}$ (Scheme 5). On the con- 
Table 2: Relative Gibbs free energy values corresponding to the transformations.

\begin{tabular}{|c|c|c|c|c|c|c|}
\hline \multirow[t]{2}{*}{ starting material } & \multicolumn{6}{|c|}{$\Delta G\left(\mathrm{~kJ} \cdot \mathrm{mol}^{-1}\right)$} \\
\hline & $1 \rightarrow 9$ & $9 \rightarrow 11$ & $11 \rightarrow 4$ & $4 \rightarrow 12$ & $12 \rightarrow 14$ & $14 \rightarrow 2$ \\
\hline $1 a$ & -4.2 & 28.2 & -6.7 & -9.7 & -14.4 & -9.4 \\
\hline $1 b$ & -6.8 & 31.5 & -13.9 & -2.8 & -17.8 & -2.9 \\
\hline $1 c$ & -19.1 & 15.6 & -7.4 & 23.5 & -34.1 & 24.1 \\
\hline 1d & -11.7 & -1.6 & 10.8 & 7.2 & -22.4 & 6.9 \\
\hline
\end{tabular}

Table 3: Relative Gibbs free energy values corresponding to the transition states.

\begin{tabular}{|c|c|c|c|c|c|c|}
\hline \multirow[t]{2}{*}{ starting material } & \multicolumn{6}{|c|}{$\Delta G^{\#}\left(\mathrm{~kJ} \cdot \mathrm{mol}^{-1}\right)$} \\
\hline & $1 T S$ & 9TS & 11TS & 4TS & $12 \mathrm{TS}$ & 14TS \\
\hline $1 a$ & 69.5 & 54.4 & 33.7 & 25.6 & 34.7 & 65.2 \\
\hline $1 b$ & 61.5 & 53.4 & 27.7 & 39.3 & 30.1 & 68.2 \\
\hline 1c & 51.2 & 48.7 & 26.7 & 40.0 & 22.0 & 68.7 \\
\hline 1d & 62.3 & 41.7 & 40.2 & 35.7 & 26.5 & 69.6 \\
\hline
\end{tabular}

trary, for isoindole $\mathbf{4 c}$ the step to $\mathbf{1 2 c}$ is endergonic (with $\Delta G=23.5 \mathrm{~kJ} \cdot \mathrm{mol}^{-1}$ ) and regioisomer 11c is energetically more advantageous, explaining the formation of the dimer of different type (8a, Scheme 6).

A closer look on the transformation of trimethoxy derivative 1d reveals that dehydration is almost isoergonic $\left(\Delta G_{\mathbf{9 d} \rightarrow \mathbf{1 1 d}}=\right.$ $\left.-1.6 \mathrm{~kJ} \cdot \mathrm{mol}^{-1}\right)$, but the formation of the isoindole intermediate $(\mathbf{1 1 d} \rightarrow \mathbf{4 d}$ ) is endergonic (unlike in the case of the three other derivatives), with a larger activation free energy $\left(\Delta G^{\#}{ }_{11 \mathrm{TS}}=\right.$ $40.2 \mathrm{~kJ} \cdot \mathrm{mol}^{-1}$ ) than those of congeners a-c. Moreover, there are two further endergonic steps in this sequence $(\mathbf{4 d} \rightarrow \mathbf{1 2 d}$, $\mathbf{1 4 d} \rightarrow \mathbf{2 d}$ ), which data altogether explain why product $\mathbf{2 d}$ was not detected at all and why cation $\mathbf{1 1 d}$ is preferred in the dimer formation, leading to product $\mathbf{8 b}$.

According to the calculations it turned out that the acid catalyst (TFA in this case), as expected, had a crucial role in the protonation and deprotonation as well as in the dehydration and hydration elementary steps of the reaction sequence. Without catalyst, the $9 \mathbf{a} \rightarrow \mathbf{1 1 a} \rightarrow \mathbf{4 a}$ transformations required an energy investment of 150.7 and $163.3 \mathrm{~kJ} \cdot \mathrm{mol}^{-1}$, instead of $54.4 \mathrm{~kJ} \cdot \mathrm{mol}^{-1}$ and $33.7 \mathrm{~kJ} \cdot \mathrm{mol}^{-1}$, calculated with TFA (Table 3 ).

In conclusion, the DFT calculations are consistent with the observation that the formation of the rearranged aldehydes $\mathbf{2 a}, \mathbf{b}$ is more favorable than that of $\mathbf{2 c , d}, \mathbf{d}$, and explain the differ- ence observed between the regiochemistry of dimers $\mathbf{3 a}, \mathbf{b}$ and 8a,b.

\section{Acid-catalyzed transformation of unsubstituted ortho-(pivaloylamino- methyl)benzaldehyde (1e)}

In order to reduce the number of possible dimer-like products, we carried out the reaction with unsubstituted $o$-(pivaloylaminomethyl)benzaldehyde (1e). Since the positional change of the two functional groups cannot be observed in this case, we could focus on the formation of the dimer-like products.

Treatment of unsubstituted derivative 1e (prepared from bromo derivative 21 [26] by formylation via lithiation) in DCM in the presence of a catalytic amount ( 0.1 equiv) of TFA for $24 \mathrm{~h}$ at room temperature led to dimer-like product $23 \mathrm{a}$ in $58 \%$ yield, obviously via the intermediate cation 22a (Scheme 8). The structure of 23a was supported by NMR data and also by single-crystal X-ray measurement (Figure 3). Nevertheless, HPLC-MS analysis of the crude product mixture showed, in addition to $23 \mathbf{a}(77 \%)$, the presence of an isomeric dimer-like product (23b, 10\%) and unreacted starting material (8\%). Due to the similar chromatographic behavior of 23b and 23a on normal phase, they were isolated from the crude product by reversed-phase preparative HPLC, then identified by detailed NMR experiments, and single-crystal X-ray measurement (Figure 3) as diastereomer racemates. When the reaction of $\mathbf{1 e}$ 
<smiles>O=Cc1ccccc1CNPN=O</smiles>

$1 \mathrm{e}$

1. BuLi, THF $\frac{-40^{\circ} \mathrm{C}, 30 \mathrm{~min}}{2 . \mathrm{DMF}}$

$1 \mathrm{~h}$<smiles>N#[PH]NCc1ccccc1Br</smiles>

21

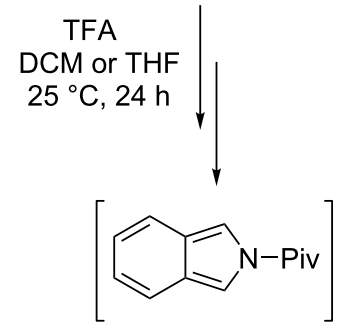

$4 \mathrm{e}$
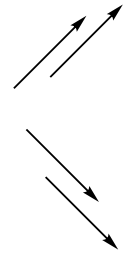

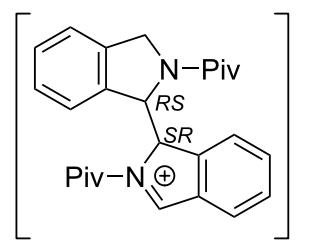

22a

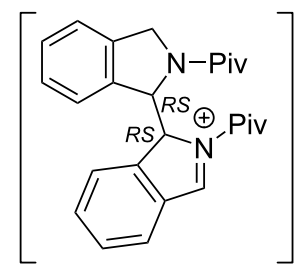

22b<smiles>N#[PH]N1Cc2ccccc2C1C(NNc1ccccc1)c1ccccc1C=O</smiles>

23a<smiles>CNC(=O)NC(c1ccccc1C=O)C1c2ccccc2CN1[PH](=O)c1ccccc1</smiles>

23b
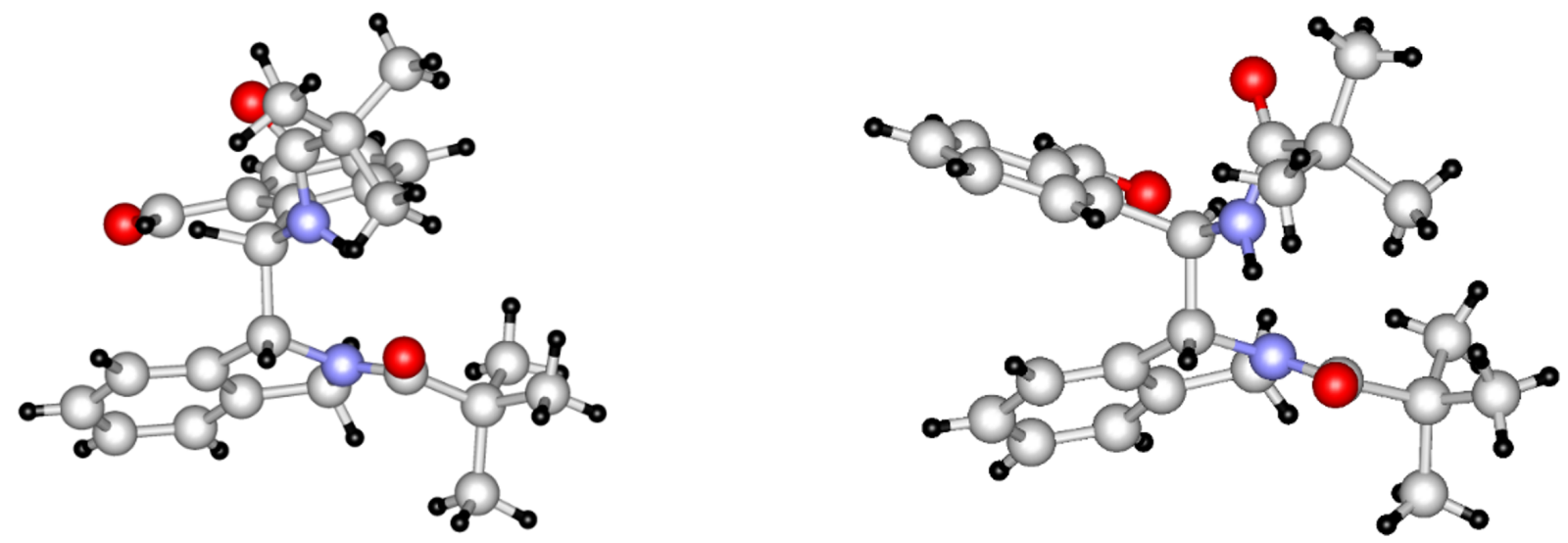

Figure 3: X-ray structures of compounds 23a (left) and 23b (right).

was carried out under the same conditions in THF instead of DCM, HPLC-MS analysis of the crude product mixture showed the presence of dimer-like product 23a $(25 \%)$, the recovered starting material 1e (67\%), and traces (ca. 1\%) of the isomeric dimer-like product (23b). After work-up, 18\% of compound 23a was obtained in addition to $51 \%$ of $1 \mathbf{e}$.

As shown in the structures, the chiral center of the isoindoline moiety in the enantiomer of compound 23a shown in Figure 3 is $R$, while the other chiral center exhibits an $S$ configuration, so its racemic form is hereinafter referred to as $R S-S R$. By the same logic, another designation for racemic $\mathbf{2 3 b}$ is $R R-S S$. The formation of intermediates $\mathbf{2 2} \mathbf{a}$ and $\mathbf{2 2} \mathbf{b}$ (Scheme 8), as the ratedetermining step leading to major product 23a $(R S-S R)$ and minor product 23b $(R R-S S)$, respectively, was also investigated by DFT level quantum chemical calculations with the same parameters as in the case of the $\mathbf{1} \rightarrow \mathbf{2}$ rearrangement. The racemic $R S$ and $R R$ forms were taken into consideration, and the computations showed that the formation of the $R S$ compound required an energy investment of $\Delta G^{\#} \mathbf{4}_{\mathbf{e} \rightarrow \mathbf{2 2} \mathbf{a}}=89.1 \mathrm{~kJ} \cdot \mathrm{mol}^{-1}$, while the reaction leading to the minor $(R R)$ isomer had a larger activation barrier $\left(\Delta G_{\mathbf{4} \rightarrow \mathbf{e} \mathbf{2 2 b}}^{\#}=101.9 \mathrm{~kJ} \cdot \mathrm{mol}^{-1}\right)$. Moreover, the formation of the latter intermediate was significantly more endergonic $\left(\Delta G_{\mathbf{4 e} \rightarrow \mathbf{2 2 b}}=69.2 \mathrm{~kJ} \cdot \mathrm{mol}^{-1}\right)$ than $\Delta G_{\mathbf{4} \mathbf{e} \rightarrow \mathbf{2 2 a}}$ $\left(37.9 \mathrm{~kJ} \cdot \mathrm{mol}^{-1}\right)$.

The structure elucidation of compounds $\mathbf{3 a}[1], \mathbf{3 b}, \mathbf{8 a}, \mathbf{b}$, and 23a,b was based on the molecular formula obtained from 
HRMS, comprehensive ${ }^{1} \mathrm{H}$ and ${ }^{13} \mathrm{C}$ NMR study and on the single-crystal X-ray structure of compounds 3a [1], 3b, 8b, 23a, and 23b (for spectra and detailed interpretation, see Supporting Information File 1). According to the single-crystal X-ray experiments of compounds $\mathbf{3 b}, \mathbf{8 b}$, and $\mathbf{2 3} \mathbf{a}$, the solid-phase structures are stabilized by a hydrogen bond between the amide $\mathrm{NH}$ and the carbonyl oxygen atom of the other amide group. The $\mathrm{H}-\mathrm{C}-\mathrm{C}-\mathrm{H}$ dihedral angles between the two asymmetric centers are not far from $90^{\circ}$ as shown by the X-ray structures of these compounds (Figure 1 and Figure 3), and also reflected by their low ${ }^{3} \mathrm{~J}(\mathrm{H}, \mathrm{H})$ coupling constants (ca. $1 \mathrm{~Hz}$ ) detected in $\mathrm{CDCl}_{3}$ solution. In the ${ }^{1} \mathrm{H}$ NMR spectra of compounds $\mathbf{3 b}, \mathbf{8 a}, \mathbf{b}$, and 23a, the $\delta \mathrm{NH}$ chemical shifts appeared in a narrow range between 9.39-9.06 ppm, indicating the presence of strong hydrogen bonds also in solution. These data suggest that the structures of the predominating conformers should be similar in the solid and liquid phases. Furthermore, we have managed to detect NOE steric proximities between the aldehyde $\mathrm{H}$ atom and the $\mathrm{H}$-C(7) (in compounds 3b, 23a) or $\mathrm{CH}_{3} \mathrm{O}-\mathrm{C}(7)$ hydrogens (in compounds $\mathbf{8 a}, \mathbf{b}$ ) of the isoindoline moiety. Supposing an $R$ configuration at the chiral center of the isoindoline unit, this kind of steric arrangement is only possible, if the other asymmetric center exists in an $S$ configuration.

As regards the minor dimer-like product $\mathbf{2 3 b}$, the high-resolution mass spectrum proposed exactly the same molecular formula as for 23a. The ${ }^{1} \mathrm{H}$ and ${ }^{13} \mathrm{C}$ spectra taken in $\mathrm{CDCl}_{3}$ solution also exhibited several similar chemical shifts to those obtained for 23a, but some interesting differences were also detected. The $\delta \mathrm{NH}=8.50 \mathrm{ppm}$ chemical shift in $\mathbf{2 3 b}$ indicates a weaker hydrogen bond, compared to the value of $9.39 \mathrm{ppm}$ obtained for 23a [27]. The detected ${ }^{3} J(\mathrm{H}, \mathrm{H})$ coupling constant for the hydrogens attached to the two asymmetric centers is $10 \mathrm{~Hz}$ in this case, indicating a dihedral angle of ca. $180^{\circ}$ in $\mathbf{2 3 b}$ Moreover, an unexpected extremely upfield aromatic $\delta \mathrm{H}(7)$ value $(5.71 \mathrm{ppm})$ was measured for the isoindoline moiety of this compound, i.e., a diamagnetic shift of ca. 1.8 ppm occurred in this position. In order to explain this phenomenon, we should consider the anisotropic effect of the aromatic rings. Such steric arrangement is only possible in case of a $R R-S S$ diastereomer (23b), with only one of the aromatic hydrogen atoms of the isoindoline moiety $[\mathrm{H}(7)]$ located in close proximity above the middle of the other aromatic ring. It can be concluded after all that the NMR data also made it possible to assign the $R S-S R$ diastereomeric structure for compounds $\mathbf{3 b}, \mathbf{8 a}, \mathbf{b}$, and $\mathbf{2 3 a}$, and the $R R-S S$ structure for congener $\mathbf{2 3 b}$.

In order to get a better insight into the stereochemistry of compounds 23a and 23b, we calculated their refined stereostructure by means of DFT geometry optimization in a DCM solution. As a result, one minimal energy conformer was identified for 23a and two for 23b (Figure 4). In the two preferred conformers of $\mathbf{2 3 b}\left(\mathbf{2 3} \mathbf{b}_{1}\right.$ and $\left.\mathbf{2 3} \mathbf{b}_{2}\right)$, the plane of the ortho-formyl-substituted phenyl rings is twisted with $180^{\circ}$ compared to each other. The Gibbs free energy difference between the two conformers is $4.1 \mathrm{~kJ} \cdot \mathrm{mol}^{-1}$ suggesting the possibility of a rotation of the ortho-formylphenyl group. Notably, conformer $\mathbf{2 3} \mathbf{b}_{\mathbf{1}}$ is the more stable one, corresponding to the structure determined by solid-phase X-ray measurements (Figure 3, right). It should be mentioned that a few signals in the NMR spectra of $\mathbf{2 3 b}$, e.g., $\delta H C-\mathrm{N}(5.71 \mathrm{dd}), \delta H C=(131.1)$, and $\delta C=(142.5)$ showed a considerable line-broadening (coalescence), revealing a partially hindered rotation of the formylphenyl moiety, i.e., the occurrence of a conformational equilibrium has to be taken into account. Even the $\delta \mathrm{HC}-\mathrm{N}$ ${ }^{13} \mathrm{C}$ NMR signal remained under the noise level, indicating that the interconversion of these conformers is slow in the NMR time-scale.

Although the NMR spectra have been measured in $\mathrm{CDCl}_{3}$, we are convinced that the conformations observed in $\mathrm{CDCl}_{3}$ are in good accordance with the ones computed considering the implicit solvent effect of DCM. Based on the structural similarity, the close dielectric constant $\left(\varepsilon=4.7\right.$ for $\mathrm{CHCl}_{3}$ and 8.9

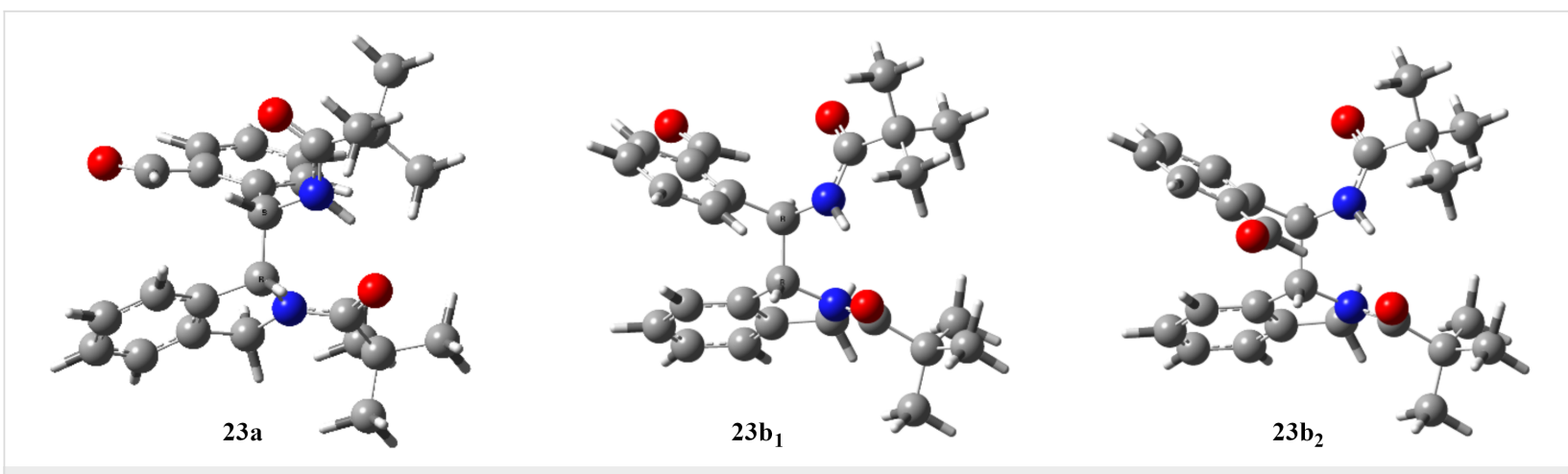

Figure 4: Structures of the minimal energy conformer of stereoisomer $\mathbf{2 3} \mathbf{a}$ and those of two minimal energy conformers of $\mathbf{2 3} \mathbf{b}\left(\mathbf{2} \mathbf{3} \mathbf{b}_{\mathbf{1}}\right.$ and $\left.\mathbf{2 3} \mathbf{b}_{\mathbf{2}}\right)$ in DCM solution, based on DFT calculations. 
for DCM) [28], the similar polarity index $\left(P=2.7\right.$ for $\mathrm{CHCl}_{3}$ and 3.1 for DCM) [29-31], and the very close dipole moment (1.15 for $\mathrm{CHCl}_{3}, 1.14$ for DCM) [32], the conformation of the compounds should be almost the same in the NMR solvent and in the DCM reaction medium. This is further supported by the recent results of Allen et al., who have shown that $\mathrm{CHCl}_{3}$ and DCM molecules exhibited the same interactions also in crystal packing [33].

\section{Conclusion}

When alkoxy-substituted $o$-(pivaloylaminomethyl)benzaldehydes 1a,b were kept in solution (DCM or THF) in the presence of a catalytic amount of TFA at room temperature, the formation of regioisomeric aldehydes $\mathbf{2 a}, \mathbf{b}$ and dimer-like products 3a,b was observed. After a similar treatment of related benzaldehydes $\mathbf{1 c}, \mathbf{d}$, only the dimer-like products $\mathbf{8 a}, \mathbf{b}$ were isolated. The transformations occur via an isoindole intermediate 4. In order to reduce the number of expected products, the similar reaction of unsubstituted $o$-(pivaloylaminomethyl)benzaldehyde (1e) was also studied. DFT calculations supported the mechanism proposed for the transformations and explained the structural differences of the dimer-like products, as well as the observed product distributions.

\section{Experimental}

Compounds 1a,b,c [2], 2a, 3a [1] and $\mathbf{2 1}$ [26] are known in the literature, while compounds $1 \mathbf{1 d}, \mathbf{e}, \mathbf{2 b}, \mathbf{3 b}, \mathbf{8 a}, \mathbf{b}$ and $\mathbf{2 3 a}, \mathbf{b}$ are new. The synthetic procedures and characterizations are given either below (2a and 3a with new synthetic procedures, and 8a, 23a) or in Supporting Information File $1(\mathbf{1 d}, \mathbf{1 e}, \mathbf{2 b}, \mathbf{3 b}, \mathbf{8 b}$, 23b). All melting points were determined on a Büchi B-540 (Flawil, Switzerland) capillary melting point apparatus and are uncorrected. IR spectra were obtained on a Bruker ALPHA FT-IR spectrometer (Billerica, MA, USA) in $\mathrm{KBr}$ pellets. ${ }^{1} \mathrm{H}$ NMR, ${ }^{13} \mathrm{C}$ NMR, DeptQ, Dept-135, edHSQC, selective HSQC, HMBC, selective HMBC, NOESY, ${ }^{1} \mathrm{H},{ }^{1} \mathrm{H}-\mathrm{COSY}$, onedimensional selective NOE, and selective TOCSY spectra were recorded at $295 \mathrm{~K}$ on a Bruker Avance III HD 600 (Billerica, MA, USA; 600 and $150 \mathrm{MHz}$ for ${ }^{1} \mathrm{H}$ and ${ }^{13} \mathrm{C}$ NMR spectra, respectively) spectrometer equipped with a Prodigy cryo-probehead. The pulse programs were taken from the Bruker software library (TopSpin 3.5) and full ${ }^{1} \mathrm{H}$ and ${ }^{13} \mathrm{C}$ assignments were achieved with widely accepted strategies $[34,35] .{ }^{1} \mathrm{H}$ NMR assignments were accomplished using general knowledge of chemical shift dispersion with the aid of the ${ }^{1} \mathrm{H}-{ }^{1} \mathrm{H}$ coupling pattern $\left({ }^{1} \mathrm{H}\right.$ NMR spectra). $\mathrm{CDCl}_{3}$ was used as the solvent and tetramethylsilane (TMS) as the internal standard. Chemical shifts $(\delta)$ and coupling constants $(J)$ are given in ppm and $\mathrm{Hz}$, respectively. The lists of the NMR signals can be found in Supporting Information File 1. To facilitate the understanding of the ${ }^{1} \mathrm{H}$ and ${ }^{13} \mathrm{C}$ signal assignments, the structures of the com- pounds are also depicted on the spectra (Supporting Information File 1 pages S3-S43). High-resolution mass spectra were recorded on a Bruker O-TOF MAXIS Impact mass spectrometer (Billerica, MA, USA) coupled with a Dionex Ultimate 3000 RS HPLC (Sunnyvale, CA, USA) system with a diode array detector. HRMS spectra of the diastereomeric 23a and 23b compounds are shown on page S44 of Supporting Information File 1. Single-crystal X-ray diffraction (SC-XRD) measurements were carried out on a Rigaku R-Axis Spider diffractometer (Tokyo, Japan) with imaging plate area detector using graphite monochromatic $\mathrm{Cu} \mathrm{K} \alpha$ radiation. SC-XRD structures were deposited at the Cambridge Crystallographic Data Centre under the following numbers: CCDC 1953421 (3a), 1953424 (3b), 1953422 (8b), 1953423 (23a) and 1958809 (23b). All reagents were purchased from commercial sources and used without further purification. The reactions were followed by analytical thin-layer chromatography on silica gel $60 \mathrm{~F}_{254}$ (Darmstadt, Germany) and on a Shimadzu LC-20 HPLC equipment coupled with an LCMS-2020 mass spectrometer (Kyoto, Japan). Purifications by flash chromatography were performed applying a Teledyne Isco Combiflash ${ }^{\circledR} \mathrm{Rf}$ system (Thousand Oaks, CA, USA) with Redisep ${ }^{\circledR}$ Rf silica flash columns using a hexane-EtOAc solvent system. The preparative HPLC separation was carried out using a Merck LaPrep Sigma LP1200 pump and a Merck LaPrep P314 UV detector, under the conditions described below for compound 23b.

The DFT level computations at the B3LYP/6-31+G (d,p) level of theory were performed considering the solvent effect of DCM using the IEFPCM solvent model with the Gaussian 09 program package. The geometries of the molecules were optimized in all cases, and frequency calculations were also performed to assure that the structures are in a local minimum or in a saddle point. This was followed by single point measurements at the B3LYP/6-311++G (3df,3pd) level of theory that resulted in the energy values presented in Table S1 (Supporting Information File 1, page S45) and used for the figures of the paper. The conformations of the reported structures have been determined by conformational analysis. The solution-phase Gibbs free energies were obtained by frequency calculations as well. The $G$ values obtained were given under standard conditions, the corrected total energies of the molecules were taken into account. Entropic and thermal corrections were evaluated for isolated molecules using standard rigid rotor harmonic oscillator approximations. That is, the Gibbs free energy was taken as the "sum of electronic and thermal free energies" printed in a Gaussian 09 vibrational frequency calculation. Standard state correction was taken into account. The transition states were optimized with the QST3 or the TS (berny) method. Transition states were identified by having one imaginary frequency in the 
Hessian matrix, and IRC calculations were performed in order to prove that the transition states connect two corresponding minima.

General procedure I for the synthesis of compounds 2a,b, 3a,b, 8a,b, and 23a. TFA ( 0.1 equiv) was added to a solution of 1a-e in DCM (20 mL). After stirring for $24 \mathrm{~h}$ at room temperature, an aqueous sodium carbonate solution $(5 \%, 7 \mathrm{~mL})$ and DCM ( $4 \mathrm{~mL})$ were added. The aqueous layer was extracted with DCM $(2 \times 4 \mathrm{~mL})$. The combined organic layer was dried over $\mathrm{MgSO}_{4}$. The solvent was evaporated and the residue purified by flash chromatography (5-30\% EtOAc in hexane). The corresponding fractions were collected, evaporated, and recrystallized from EtOAc/hexane to afford the title compounds as white solids.

General procedure II for the synthesis of compounds $\mathbf{2 a , b}$, 3a,b, 8a,b and 23a. TFA ( 0.1 equiv) was added to a solution of 1a-e in THF $(20 \mathrm{~mL})$. After stirring for $24 \mathrm{~h}$ at room temperature, an aqueous sodium carbonate solution $(5 \%, 7 \mathrm{~mL})$ and DCM (4 mL) were added. The aqueous layer was extracted with DCM $(2 \times 4 \mathrm{~mL})$. The combined organic layer was dried over $\mathrm{MgSO}_{4}$. The solvent was evaporated and the residue purified by flash chromatography (5-30\% EtOAc in hexane). The corresponding fractions were collected, evaporated, and recrystallized from EtOAc/hexane to afford the title compounds as white solids.

$N$-[(5-Formyl-2H-1,3-benzodioxol-4-yl)methyl]-2,2dimethylpropanamide (2a) [1]. Method A: This compound was prepared according to general procedure I using 1a [2] (1.02 g, $3.88 \mathrm{mmol})$ and TFA ( $30 \mu \mathrm{L}, 44 \mathrm{mg}, 0.39 \mathrm{mmol})$. The title compound (517 mg, 51\%) was isolated as white solid. Mp 125-126 ${ }^{\circ} \mathrm{C}$ (EtOAc/hexane); IR (KBr): vNH 3344, vCH 3082 , $v \mathrm{HC}=\mathrm{O} 1682, v \mathrm{C}=\mathrm{O}$ (amide) $1641, v \mathrm{C}=\mathrm{C}(\mathrm{Ar}) 1596,1494$ $v_{\text {as }} \mathrm{C}-\mathrm{O}-\mathrm{C} 1268, v_{s} \mathrm{C}-\mathrm{O}-\mathrm{C} 1064 \mathrm{~cm}^{-1}$; HRMS $(\mathrm{m} / \mathrm{z}):[\mathrm{M}+\mathrm{H}]^{+}$ calcd for $\mathrm{C}_{14} \mathrm{H}_{18} \mathrm{NO}_{4}{ }^{+}$264.1230; found: 264.1229; anal. calcd for $\mathrm{C}_{14} \mathrm{H}_{17} \mathrm{NO}_{4}(263.29)$ : $\mathrm{N}, 5.32 ; \mathrm{H}, 6.51 ; \mathrm{C}, 63.87$; found: $\mathrm{N}$, $5.38 ; \mathrm{H}, 6.44 ; \mathrm{C}, 63.77 \%$; NMR data are identical with those published earlier [1].

Method B: This compound was prepared according to general procedure II using 1a [2] (1.00 g, $3.80 \mathrm{mmol})$ and TFA ( $29 \mu \mathrm{L}$, $43 \mathrm{mg}, 0.38 \mathrm{mmol}$ ). The title compound (592 mg, 59\%) was isolated as white solid. Analytical data are identical with those described in Method A.

$N$-[(S,R)-[(6R,S)-7-(2,2-Dimethylpropanoyl)-2H,6H,7H,8H$[1,3]$ dioxolo[4,5- $e$ ]isoindol-6-yl](5-formyl-2H-1,3-benzodioxol-4-yl)methyl]-2,2-dimethylpropanamide (3a) [1], Method A: This compound was prepared according to general proce- dure I using 1a [2] (1.02 g, $3.88 \mathrm{mmol})$ and TFA $(30 \mu \mathrm{L}$, $44 \mathrm{mg}, 0.39 \mathrm{mmol})$. The title compound (135 mg, 13\%) was isolated as a white solid. Mp $248-250{ }^{\circ} \mathrm{C}$ (EtOAc/hexane); IR $(\mathrm{KBr}): v \mathrm{NH} 3336, v \mathrm{CH} 3088, v \mathrm{HC}=\mathrm{O} 1680, v \mathrm{C}=\mathrm{O}$ (amide) $1659, v \mathrm{C}=\mathrm{C}(\mathrm{Ar}) 1614,1474, v_{\text {as }} \mathrm{C}-\mathrm{O}-\mathrm{C} 1257, v_{s} \mathrm{C}-\mathrm{O}-\mathrm{C}$ $1052 \mathrm{~cm}^{-1}$; HRMS $(\mathrm{m} / \mathrm{z}):[\mathrm{M}+\mathrm{H}]^{+}$calcd for $\mathrm{C}_{28} \mathrm{H}_{33} \mathrm{~N}_{2} \mathrm{O}_{7}{ }^{+}$ 509.2283; found: 509.2284; anal. calcd for $\mathrm{C}_{28} \mathrm{H}_{32} \mathrm{~N}_{2} \mathrm{O}_{7}$ (508.57): N, 5.51; H, 6.34; C, 66.13\%; found: N, 5.52; H, 6.13; C, $65.90 \%$. NMR data are identical with those published earlier [1].

Method B: This compound was prepared according to general procedure II using 1a [2] (1.00 g, $3.80 \mathrm{mmol})$ and TFA (29 $\mu \mathrm{L}$, $43 \mathrm{mg}, 0.38 \mathrm{mmol}$ ). The title compound ( $42 \mathrm{mg}, 4 \%$ ) was isolated as a white solid. Analytical data are identical with those described in Method A.

$N$-[(S,R)-[(1R,S)-2-(2,2-Dimethylpropanoyl)-7-methoxy-2,3dihydro-1H - is oindol-1-yl] (2-formy -3-methoxy phenyl)methyl\}-2,2-dimethylpropanamide (8a). Method A: This compound was prepared according to general procedure I using 1c [2] (1.01 g, $4.06 \mathrm{mmol})$ and TFA (31 $\mu \mathrm{L}, 46 \mathrm{mg}$, $0.41 \mathrm{mmol})$. The title compound $(78 \mathrm{mg}, 8 \%)$ was isolated as white solid. Mp 169-171 ${ }^{\circ} \mathrm{C}$ (EtOAc/hexane); IR (KBr): vNH 3291, vCH 3027, $v \mathrm{HC}=\mathrm{O} 1695, v \mathrm{C}=\mathrm{O}$ (amide) 1663, $v \mathrm{C}=\mathrm{C}$ (Ar) 1612, 1527, v as C-O-C 1276, $v_{s} \mathrm{C}-\mathrm{O}-\mathrm{C} 1074 \mathrm{~cm}^{-1}$; HRMS $(\mathrm{m} / \mathrm{z})$ : $[\mathrm{M}+\mathrm{H}]^{+}$calcd for $\mathrm{C}_{28} \mathrm{H}_{37} \mathrm{~N}_{2} \mathrm{O}_{5}{ }^{+} 481.2697$; found: 481.2681; anal. calcd for $\mathrm{C}_{28} \mathrm{H}_{36} \mathrm{~N}_{2} \mathrm{O}_{5}$ (480.61): N, 5.83; $\mathrm{H}, 7.55$; C, 69.98\%; found: N, 5.87; H, 7.36; C, 69.83\%. ${ }^{1} \mathrm{H}$ and ${ }^{13} \mathrm{C}$ spectra are shown on page S19 of Supporting Information File 1. Hydrogen-hydrogen connectivities were elucidated utilizing the ${ }^{1} \mathrm{H},{ }^{1} \mathrm{H}$-COSY experiment (page S20, Supporting Information File 1). The detected low ${ }^{3} J(\mathrm{H}, \mathrm{H})$ coupling constant (ca. $1 \mathrm{~Hz}$ ) revealed also in this case a dihedral angle of nearly $90^{\circ}$ for the $\mathrm{H}-\mathrm{C}-\mathrm{C}-\mathrm{H}$ moiety. One-dimensional sel-NOE experiments on signals 9.78, 6.88, 6.30, 5.91, 4.59, and 3.42 elucidated the characteristic steric proximities (pages S21 and S22 in Supporting Information File 1) and proved the $S R-R S$ type structure. The ${ }^{13} \mathrm{C}$ signal assignment was supported with HSQC and HMBC spectra (pages S23 and S24 in Supporting Information File 1).

Method B: This compound was prepared according to general procedure II using 1c [2] (1.00 g, $4.02 \mathrm{mmol})$ and TFA (31 $\mu \mathrm{L}$, $46 \mathrm{mg}, 0.40 \mathrm{mmol})$. The title compound $(71 \mathrm{mg}, 7 \%)$ was isolated as white solid. Analytical data are identical with those described in Method A.

$N$-[(S,R)-[(1R,S)-2-(2,2-Dimethylpropanoyl)-2,3-dihydro$1 H$-isoindol-1-yl](2-formylphenyl)methyl]-2,2-dimethylpropanamide (23a). Method A: This compound was prepared 
according to general procedure I using $1 \mathrm{e}(1.01 \mathrm{~g}, 4.61 \mathrm{mmol})$ and trifluoroacetic acid $(35 \mu \mathrm{L}, 53 \mathrm{mg}, 0.46 \mathrm{mmol})$. The title compound (584 mg, 58\%) was isolated as white solid. Mp 156-158 ${ }^{\circ} \mathrm{C}$ (EtOAc/hexane); IR (KBr): vNH 3314, vCH 2965, $v \mathrm{HC}=\mathrm{O} 1693, v \mathrm{C}=\mathrm{O}$ (amide) 1657, $v \mathrm{C}=\mathrm{C}(\mathrm{Ar})$ 1613, $1481 \mathrm{~cm}^{-1}$; HRMS $[\mathrm{M}+\mathrm{H}]^{+}$calcd for $\mathrm{C}_{26} \mathrm{H}_{33} \mathrm{~N}_{2} \mathrm{O}_{3}{ }^{+} 421.2491$; found: 421.2484; anal. calcd for $\mathrm{C}_{26} \mathrm{H}_{32} \mathrm{~N}_{2} \mathrm{O}_{3}$ (420.55): N, 6.66; H, 7.67; C, 74.26\%; found: N, 6.70; H, 7.42; C, 73.98\%. The ${ }^{1} \mathrm{H}$ spectrum is shown on page S32 of Supporting Information File 1. The two-dimensional NOESY experiment (page S33 in Supporting Information File 1) revealed the characteristic steric proximities and proved the $S R-R S$-type structure. The ${ }^{13} \mathrm{C}$ signal assignment (page S34 in Supporting Information File 1) was supported by edHSQC and HMBC measurements, together with their band selective versions (pages S35-S37 in Supporting Information File 1).

Method B: This compound was prepared according to general procedure II using 1e (1.03 g, $4.70 \mathrm{mmol})$ and TFA (36 $\mu \mathrm{L}$, $54 \mathrm{mg}, 0.47 \mathrm{mmol}$ ). The title compound (182 mg, 18\%) was isolated as white solid. Analytical data are identical with those described in Method A.

\section{Supporting Information}

Detailed NMR studies $\left({ }^{1} \mathrm{H}\right.$ NMR, ${ }^{13} \mathrm{C}$ NMR, DeptQ, Dept-135, edHSQC, selective HSQC, HMBC, selective HMBC, NOESY, ${ }^{1} \mathrm{H},{ }^{1} \mathrm{H}-\mathrm{COSY}$, one-dimensional selective NOE, selective TOCSY spectra) of new compounds;

HRMS spectra of compounds 23a and 23b; coordinates and energy values of the computed structures; cif files and structure report files of compounds $\mathbf{3 a}, \mathbf{3 b}, \mathbf{8 b}, \mathbf{2 3 a}, \mathbf{2 3 b}$.

\section{Supporting Information File 1}

Detailed NMR studies.

[https://www.beilstein-journals.org/bjoc/content/

supplementary/1860-5397-16-136-S1.pdf]

\section{Supporting Information File 2}

Crystallographic information files for compounds $\mathbf{3 a}, \mathbf{3 b}$,

8b, 23a, and 23b.

[https://www.beilstein-journals.org/bjoc/content/ supplementary/1860-5397-16-136-S2.zip]

\section{Acknowledgements}

This paper is partly based on the Ph.D. thesis of the first author, Dr. Csilla Hargitai (https://repozitorium.omikk.bme.hu/ bitstream/handle/10890/13349/ertekezes.pdf). The authors are grateful to Dr. Gábor Németh for a careful reading of the manuscript.

\section{ORCID ${ }^{\circledR}$ iDs}

Péter Ábrányi-Balogh - https://orcid.org/0000-0002-9284-5160 András Dancsó - https://orcid.org/0000-0001-8460-217X

Gyula Simig - https://orcid.org/0000-0002-2569-6476

Balázs Volk - https://orcid.org/0000-0002-2019-1874

\section{References}

1. Hargitai, C.; Koványi-Lax, G.; Nagy, T.; Ábrányi-Balogh, P.; Dancsó, A.; Halász, J.; Tóth, G.; Simig, G.; Volk, B. Monatsh. Chem. 2019, 150, 1121-1125. doi:10.1007/s00706-019-02395-6

2. Simig, G. Synlett 1990, 425-426. doi:10.1055/s-1990-21116

3. White, J. D.; Mann, M. E. Adv. Heterocycl. Chem. 1969, 10, 113-147. doi:10.1016/s0065-2725(08)60496-1

4. Babichev, F. S.; Kovtunenko, V. A.; Tyltin, A. K. Russ. Chem. Rev. 1981, 50, 1087-1103. doi:10.1070/rc1981v050n11abeh002738 Chem. Abstr. 1982, 96, 52083 f.

5. Bonnett, R.; North, S. A. Adv. Heterocycl. Chem. 1981, 29, 341-399. doi:10.1016/s0065-2725(08)60790-4

6. Bender, C. O.; Bonnett, R. Chem. Commun. 1966, 198-199. doi:10.1039/c19660000198

7. Potts, H. A.; Smith, G. F. J. Chem. Soc. 1957, 4018-4022. doi:10.1039/jr9570004018

8. Smith, G. F. Adv. Heterocycl. Chem. 1963, 2, 287-309. doi:10.1016/s0065-2725(08)60752-7

9. Bonnett, R.; Brown, R. F. C.; Smith, R. G. J. Chem. Soc., Perkin Trans. 1 1973, 1432-1436. doi:10.1039/p19730001432

10. Kreher, R.; Seubert, J. Tetrahedron Lett. 1966, 7, 3015-3019. doi:10.1016/s0040-4039(01)99905-8

11. Fryer, R. I.; Brust, B.; Earley, J. V.; Sternbach, L. H. J. Chem. Soc. C 1967, 366-367. doi:10.1039/j39670000366

12. Bonnett, R.; North, S. A.; Newton, R. F.; Scopes, D. I. C. Tetrahedron 1983, 39, 1401-1405. doi:10.1016/s0040-4020(01)91911-8

13. Kreher, R. P.; Feldhoff, U.; Jelitto, F. Z. Naturforsch., B: J. Chem. Sci. 1988, 43, 1332-1340. doi:10.1515/znb-1988-1020 Chem. Abstr. 1989, 110, 231373.

14. Kreher, R. P.; Use, G. Chem. Ber. 1989, 122, 337-342. doi:10.1002/cber.19891220222

15. Kreher, R. P.; Kohl, N. Chem.-Ztg. 1986, 110, 299-303. Chem. Abstr. 1987, 107, 77557.

16. Use, G.; Kreher, R. P. Chem.-Ztg. 1982, 106, 143-144. Chem. Abstr. 1982, 96, 217637.

17. Donohoe, T. J. Sci. Synth. 2001, 10, 661. doi:10.1055/sos-sd-010-00811

18. Joule, J. A.; Mills, K. Heterocyclic Chemistry, 4th ed.; Blackwell Science Ltd.: Oxford, UK, 2000.

19. Gaussian 09, Revision D.01; Gaussian, Inc.: Wallingford, CT, 2009.

20. Becke, A. D. J. Chem. Phys. 1993, 98, 5648-5652. doi:10.1063/1.464913

21. Stephens, P. J.; Devlin, F. J.; Chabalowski, C. F.; Frisch, M. J. J. Phys. Chem. 1994, 98, 11623-11627. doi:10.1021/j100096a001

22. Petersson, G. A.; Bennett, A.; Tensfeldt, T. G.; Al-Laham, M. A.; Shirley, W. A.; Mantzaris, J. J. Chem. Phys. 1988, 89, 2193-2218. doi:10.1063/1.455064

23. Becke, A. D. J. Chem. Phys. 2014, 140, 18 A301. doi:10.1063/1.4869598

24. McLean, A. D.; Chandler, G. S. J. Chem. Phys. 1980, 72, 5639-5648. doi:10.1063/1.438980 
25. Miertuš, S.; Scrocco, E.; Tomasi, J. Chem. Phys. 1981, 55, 117-129. doi:10.1016/0301-0104(81)85090-2

26. Smith, K.; El-Hiti, G. A.; Hegazy, A. S.; Fekri, A.; Kariuki, B. M ARKIVOC 2009, No. xiv, 266-300. doi:10.3998/ark.5550190.0010.e24

27. Friebolin, H. Ein- und zweidimensionale NMR-Spektroskopie: eine Einführung; Wiley-VCH: Weinheim, Germany, 2006.

See for a detailed discussion on the influence of the strength of a hydrogen bond to the ${ }^{1} \mathrm{H}$ NMR chemical shifts.

28. https://depts.washington.edu/eooptic/linkfiles/dielectric_chart\%5B1\%5D .pdf. https://depts.washington.edu/eooptic/linkfiles/dielectric_chart\%5B1\%5D .pdf

29. Harris, D. C. Quantitative Chemical Analysis, 9th ed.; W. H. Freeman \& Co.: New York, NY, USA, 2015.

30. Katz, E.; Eksteen, R.; Schoenmakers, P.; Miller, N., Eds. Handbook of HPLC; CRC Press: Boca Raton, FL, USA, 1998. doi:10.1201/9780203909751

31. https://sites.google.com/site/chempendix/hplc/solvent-polarity-index.

32. https://people.chem.umass.edu/xray/solvent.html. https://people.chem.umass.edu/xray/solvent.html

33. Allen, F. H.; Wood, P. A.; Galek, P. T. A. Acta Crystallogr., Sect. B: Struct. Sci., Cryst. Eng. Mater. 2013, 69, 379-388. doi:10.1107/s2052519213015078

34. Duddeck, H.; Dietrich, W.; Tóth, G. Structure elucidation by modern NMR; Springer-Steinkopff: Darmstadt, Germany, 1998. doi:10.1007/978-3-642-88310-1

35. Pretsch, E.; Tóth, G.; Munk, M. E.; Badertscher, M. Computer-aided structure elucidation. Spectra interpretation and structure generation; Wiley-VCH: Weinheim, Germany, 2002

\section{License and Terms}

This is an Open Access article under the terms of the Creative Commons Attribution License (http://creativecommons.org/licenses/by/4.0). Please note that the reuse, redistribution and reproduction in particular requires that the authors and source are credited.

The license is subject to the Beilstein Journal of Organic Chemistry terms and conditions:

(https://www.beilstein-journals.org/bjoc)

The definitive version of this article is the electronic one which can be found at: doi:10.3762/bjoc. 16.136 